\title{
Effect of block copolymers of various molecular architecture on the phase morphology and tensile properties of LDPE rich (LDPE/PS) blends
}

\author{
C. Harrats ${ }^{\mathrm{a}}$, R. Fayt ${ }^{\mathrm{b}}$ and R. Jérôme ${ }^{\mathrm{b}}$ \\ ${ }^{a}$ Laboratory for Macromolecular Structural Chemistry, Department of Chemistry, Katholieke \\ Universiteit Leuven, Celestijnenlaan, 200 F, 3001, Heverlee, Belgium \\ ${ }^{\mathrm{b}}$ Center for Education and Research on Macromolecules, Bat B6 de Chimie ULg-Sart- \\ Tilman, Liège, Belgium
}

\begin{abstract}
The emulsification efficiency of three different block copolymers consisting of hydrogenated polybutadiene (HPB) and polystyrene (PS), i.e. a pure diblock, a tapered diblock and a triblock copolymer has been compared in low density polyethylene/polystyrene (LDPE/PS) blends rich in polyethylene. The comparison relies upon the ability of these potential interfacial agents to stabilize fine phase dispersion and to promote good interfacial adhesion. Based on the phase morphology, the ultimate tensile properties and the dynamic viscosity of the modified blends, the tapered diblock copolymer is clearly the most efficient emulsifier. For instance a plateau is observed in the property-copolymer content dependence when $2 \mathrm{wt} \%$ tapered diblock are used compared to ca. $5 \mathrm{wt} \%$ in case of the pure diblock. In contrast, no plateau is observed when the triblock copolymer is used. This is assumed to result from a less quantitative localization of these two copolymers i.e. the pue diblock or the triblock at the LDPE/PS interface.
\end{abstract}

Keywords: Copolymer; Emulsification; Phase morphology

\section{Introduction}

When one of the two constitutive components of a binary immiscible polymer blend is minor, a dispersed phase morphology is observed as a result of a dominant break-up of the minor phase at least below a critical volume fraction. As an extension of the contributions by Elemans [1] and Elmendorpf [2], Janssen [3] has modeled this break-up phase process under various deformation conditions (hyperbolic flow, simple shear and extensional flow). In the absence of any emulsifier, the equilibrium particle size is controlled by the melt viscosity ratio of the particles to the matrix. This prediction has been confirmed experimentally [4].

Nevertheless, when the volume fraction of the dispersed phase increases, the average size of this phase increases as a result of a steadily more important competition between the rupture process and the particles coalescence [1-3]. This phenomenon was observed even in compatibilized blends when the compatibilizer does not exhibit a good interaction balance to favor its stable location at the interface between the blend components [5]. Nowadays, it is known that the average particle size and thus the relative effect of coalescence can be decreased by the addition of interfacial agents, i.e. grafts or block copolymers [6-9]. The efficiency of these copolymers in preventing coalescence from occurring however strongly depends on their molecular architecture, molecular weight composition and content. More than 15 years ago, the effect of the molecular structure of block copolymers consisting of hydrogenated polybutadiene (HPB) and polystyrene (PS), was studied on the mechanical properties of polyethylene/polystyrene blends [10]. The copolymer content used was however in the range of 6-10 wt\%. Block copolymers were found to be more efficient than grafts, and 
when block copolymers were compared, the diblock structure was preferred to the triblock one.

The isothermal stability of a co-continuous two-phase morphology has recently been considered as a very sensitive test of the capability of a copolymer to stabilize the dispersion of PE and PS phases above their melting and glass transition temperatures, respectively, [1112]. Although slower compared to the co-continuous phase morphology, the instability of dispersed phase morphology is increasingly dealt with. Even in quiescent conditions, i.e. in the absence of any mechanical shear, phase growth was found to be much more important than would be expected [13]. It is worth noting that phase coalescence has been modeled for unsheared blends containing a dispersed phase of an average particle size of $1 \mu \mathrm{m}$ and a volume fraction of 0.25 . A restricted coalescence was predicted when the matrix viscosity exceeds $495 \mathrm{~Pa} \mathrm{~s}$ [14]. Significant coalescence was also reported within $10 \mathrm{~min}$ in the case of a matrix ( $80 \mathrm{vol} \%$ ) of a much higher viscosity (9500 Pa s) [15]. Phase coalescence, under quiescent conditions, in immiscible polymer blends prepared by solvent casting was also considered. In this system the author described coalescence as an aggregation process [16]. A process of the movement by translation of the small particles was assumed. When particles are close enough the flattened interface of the matrix breaks down in favor of particles sintering. EPR phase growth in a PP matrix has been discussed in terms of Ostwald ripening as usually met in metastable homogenous binary blends [17].

The present paper will focus on the emulsification efficiency of three different block copolymers consisting of HPB and PS, i.e. a pure diblock, a tapered diblock and a triblock, in low density polyethylene (LDPE) rich LDPE/PS blends.

The emulsification curves, the ultimate tensile properties and the melt viscosity of the modified blends will be used as criteria of analysis. Furthermore, the dependence of the phase morphology and ultimate tensile properties on annealing above the melt and glass transition temperatures of the blend components will also be discussed.

\section{Materials and experimental}

\subsection{Materials}

A LDPE, Shell 33 from Shell $\left(\overline{M_{n}} \approx 40000\right)$.and a PS, Polystyrol $158 \mathrm{~K}$ from BASF $\left(\overline{M_{n}} \approx 100000\right)$, were used throughout this study. The pure and tapered PB- $b$-PS copolymers were locally prepared via classical living anionic polymerization. Hydrogenation of the PB blocks was performed with a ziegler-type catalyst. Both copolymers have the same styrene content (50 wt\%). In other words, $\overline{\mathrm{M}_{\mathrm{s}}}$ of each block for the pure diblock is 35,000 whereas the tapered sample can be schematically described by the sequence of partial molecular weights $23,000-19,000-28,000$ for PS- $b-\mathrm{P}(\mathrm{S}-c o-\mathrm{B})-b-\mathrm{PB}$. The triblock copolymer selected was a commercial grade, Kraton G1652, from Shell. It consists of PS- $b$-P(E-co-B)- $b$-PS blocks having respective molecular weights of 7,500-35,000-7,500. This particular grade of relatively low molecular weight compared to the pure and the tapered copolymers was selected on the basis of previous experiments performed in our laboratory and also reported in [18-19]. Indeed this grade was found to be more efficient for the emulsification of LDPE/PS and EPR/PS than other grades of higher molecular weights and therefore of very high viscosity. 


\subsection{Blend preparation}

Polymers were melt-blended with a laboratory two-roll mill at $200^{\circ} \mathrm{C}$ for $5 \mathrm{~min}$, the average roll speed being $27 \mathrm{rpm}$. These mixing conditions allowed an equilibrium dispersion to be reached. The copolymer was blended with the minor phase before adding the major constitutive component. After mixing, blends were compression molded into $1 \mathrm{~mm}$ thick sheets at $200^{\circ} \mathrm{C}$ for $5 \mathrm{~min}$. These sheets were annealed at $180^{\circ} \mathrm{C}$ for $150 \mathrm{~min}$, and then quenched by rapid transfer in a press at $25^{\circ} \mathrm{C}$.

\subsection{Microscopy observation and particle size measurement}

The phase morphology of the 80LDPE/20PS blends, consisting of PS discrete particles dispersed in the LDPE matrix was observed by scanning electron microscopy (SEM) on goldpalladium coated surfaces. Prior to the SEM observation, fracture surfaces were cryosmoothed and treated with THF in order to dissolve selectively the dispersed PS phases from the surface. The phase contrast was accordingly increased, and the micrographs were treated by image analysis according to standard granulometry technique (based on the gray level), as follows: the information stored by the SEM micrograph was transferred to a monitor by a video camera. The obtained image was converted to the inverted binary image. Then successive image filtration, including erosion, dilatation and iteration were carried out, such that the convexity and the incomplete particles on the screen border were eliminated. Finally, the surface area of the particles was computed. To minimize the statistical errors, an average of 200-400 particles per sample were considered. More than one SEM micrograph per sample was usually analyzed. Since all the particles observed were not systematically cut through their equator, a correction was applied as previously reported by $\mathrm{Wu}$ [20]. The accuracy of the particle size calculated by the computer-aided image analysis was ascertained by the manual and direct measurement of the size of a reference particle (the largest possible one).

Ultimate tensile properties (tensile strength and elongation at break) were measured for test specimens cut from the molded and annealed sheets according to DIN53448, with a Adhamel Lhomargy DY 24 tensile tester at room temperature and at a cross-head speed of $2 \mathrm{~cm} / \mathrm{min}$. Each reported value was the average of five independent tests.

The dynamic melt viscosity was measured as a function of frequency using a Rheometrics Mechanical Spectrometer, RMS800 at a constant temperature of $180^{\circ} \mathrm{C}$. Parallel plates geometry was used. Disk shaped specimens of a $25 \mathrm{~mm}$ diameter were machined from the molded $1 \mathrm{~mm}$ thick sheets. To determine the limit, of linear viscoelasticity, the storage modulus, $G^{\prime}$, of each sample was measured as a function of strain. Finally, a $10 \%$ strain was found to be suited to all samples in this study. Furthermore, a time sweep test was carried out in order to ascertain the thermal stability of the samples during measurement. Thus, all the dynamic measurements were performed at $180^{\circ} \mathrm{C}$, with a $10 \%$ strain and a frequency sweep in the range of $5 \times 10^{-2}-10^{+2} \mathrm{rad} / \mathrm{s}$.

\section{Results and discussion}

\subsection{Emulsification characteristics}

In the series of SEM micrographs of uncompatibilized 80LDPE/20PS (Fig. 1) and Tapered $(\mathrm{Tp})$, Pure (Pr) and Triblock (Tr) compatibilized blends shown in Fig. 2, Fig. 3 and Fig. 4 , respectively, the effect of the interfacial agents on PS particle size can be qualitatively 
appreciated by visual observation. These micrographs reveal clearly that upon addition of a copolymer (at any concentration), the PS dispersed particles exhibit significant size reduction. The emulsification action of a copolymer in immiscible blends has now become a known and a very common fact. What still remains ambiguous and not really elucidated in a rational way is to which extent the emulsification efficiency depends on the molecular architecture and characteristics of the copolymer emulsifier.

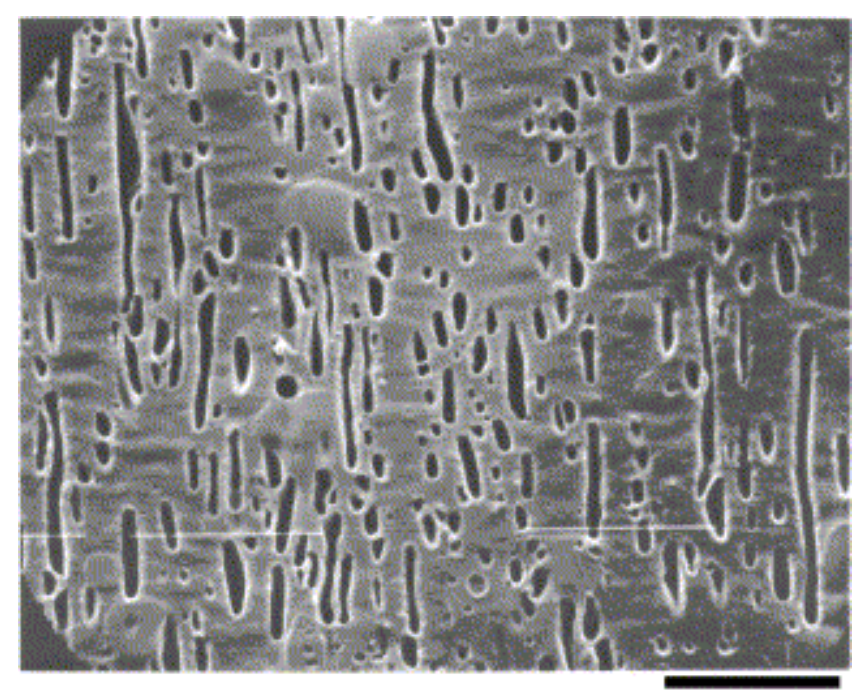

\section{$10 \mathrm{u}$}

Fig. 1. SEM of cryo-smoothed and THF etched surfaces of 80LDPE/20PS without copolymer. 
(a)
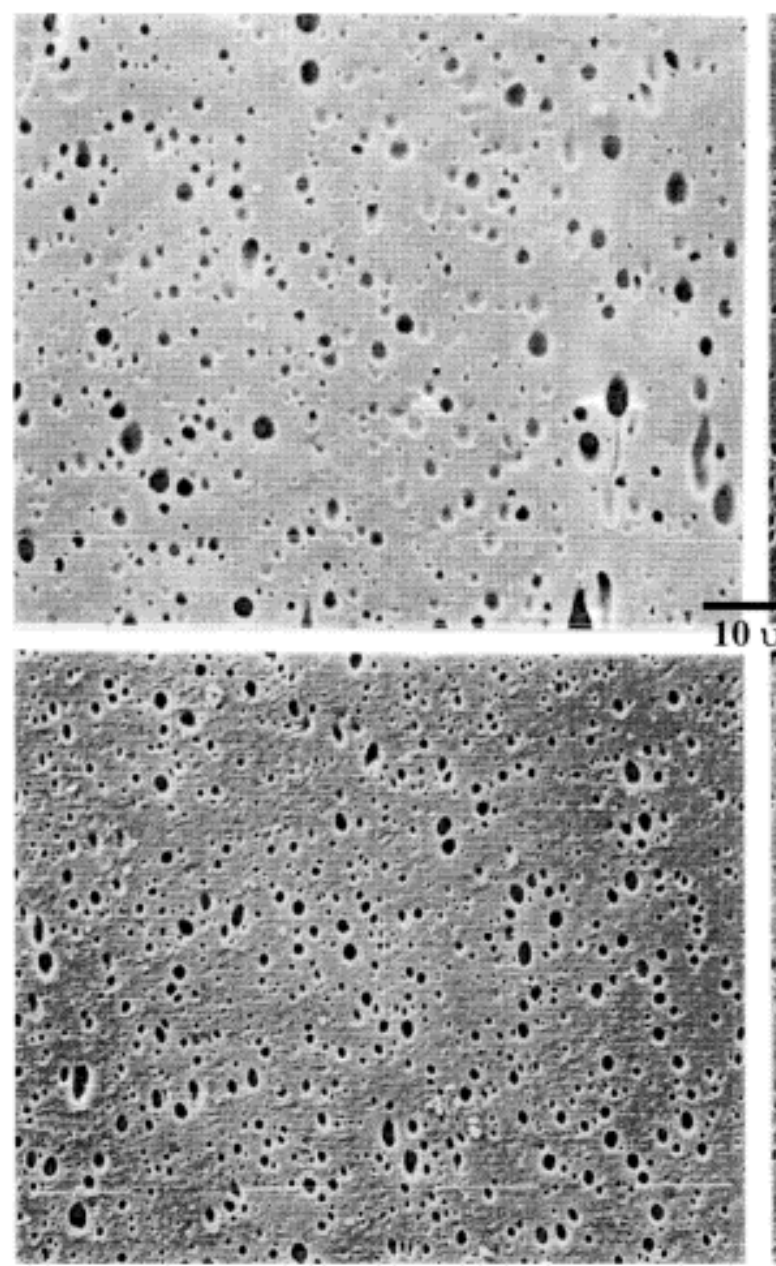

(c) (b)
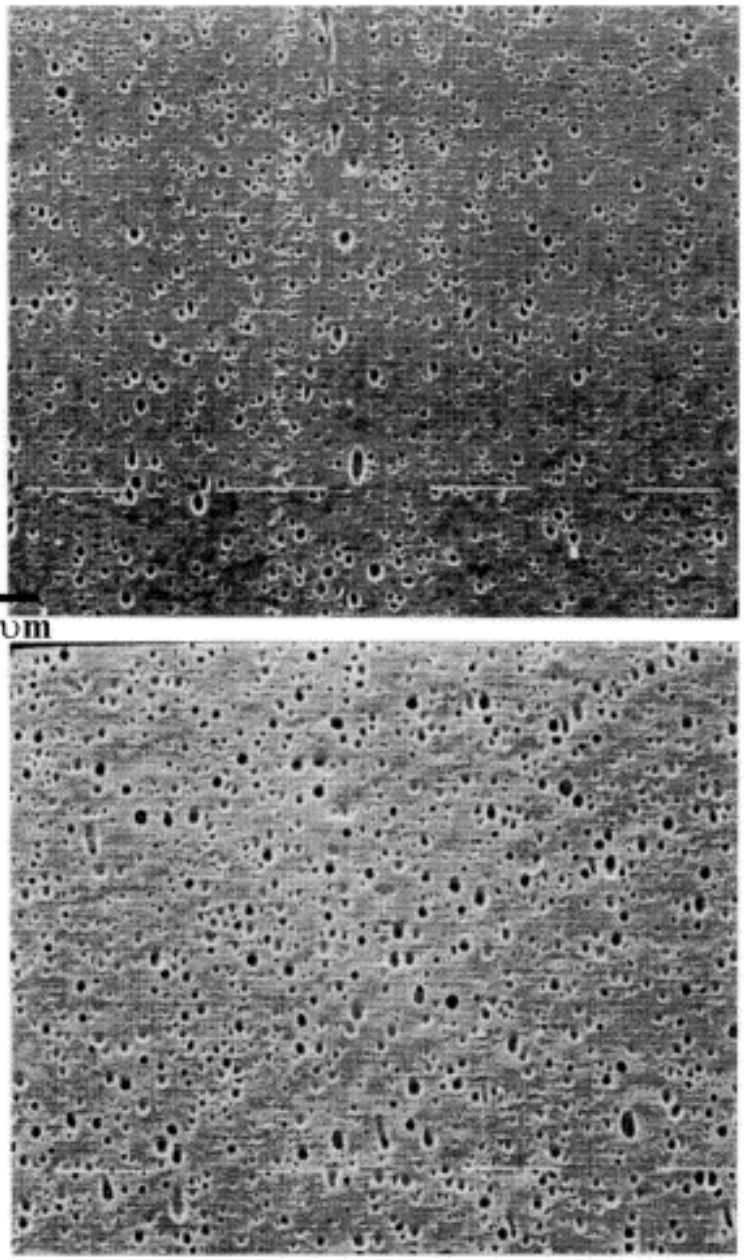

(d)

Fig. 2. SEM of cryo-smoothed and THF etched surfaces of 80LDPE/20PS+(Tp) Tapered diblock: (a) 1, (b) 2, (c) 5 and (d) $10 w t \%$. 
(a)

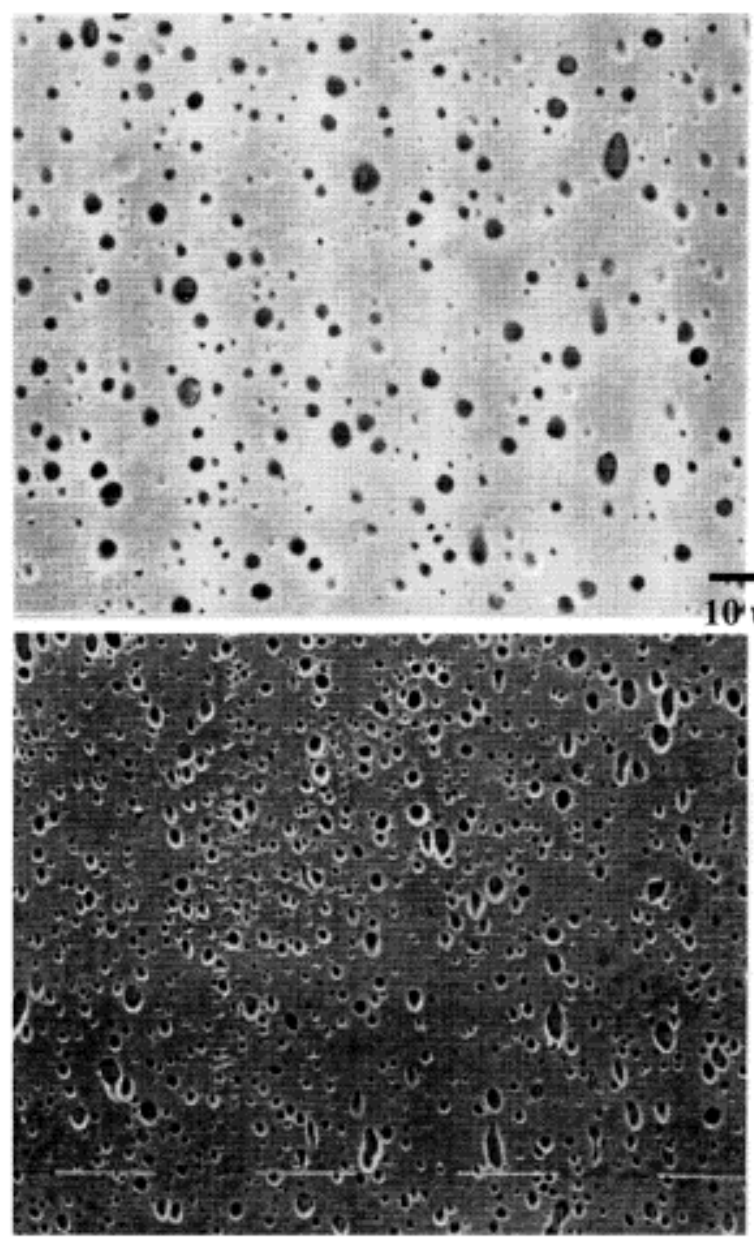

(c) (b)
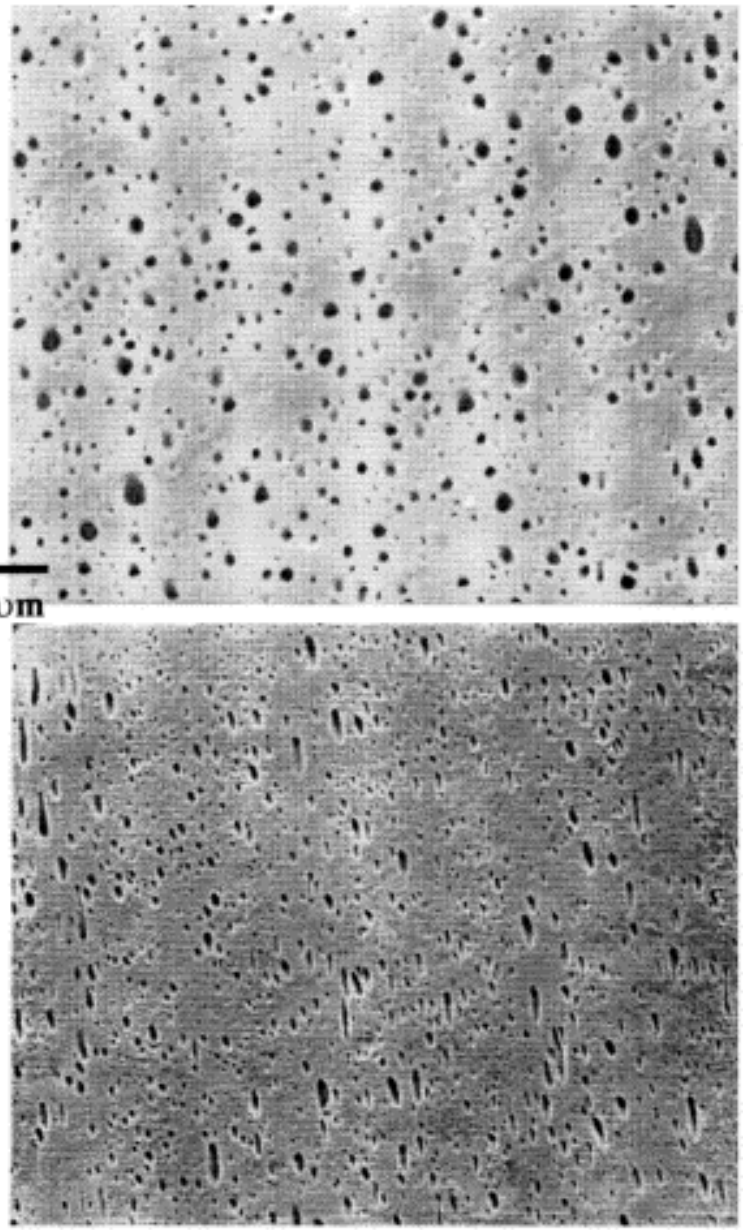

(d)

Fig. 3. SEM of cryo-smoothed and THF etched surfaces of $80 L D P E / 20 P S+(P r)$ Pure diblock: (a) 1, (b) 2, (c) 5 and (d) $10 w t \%$. 
(a)

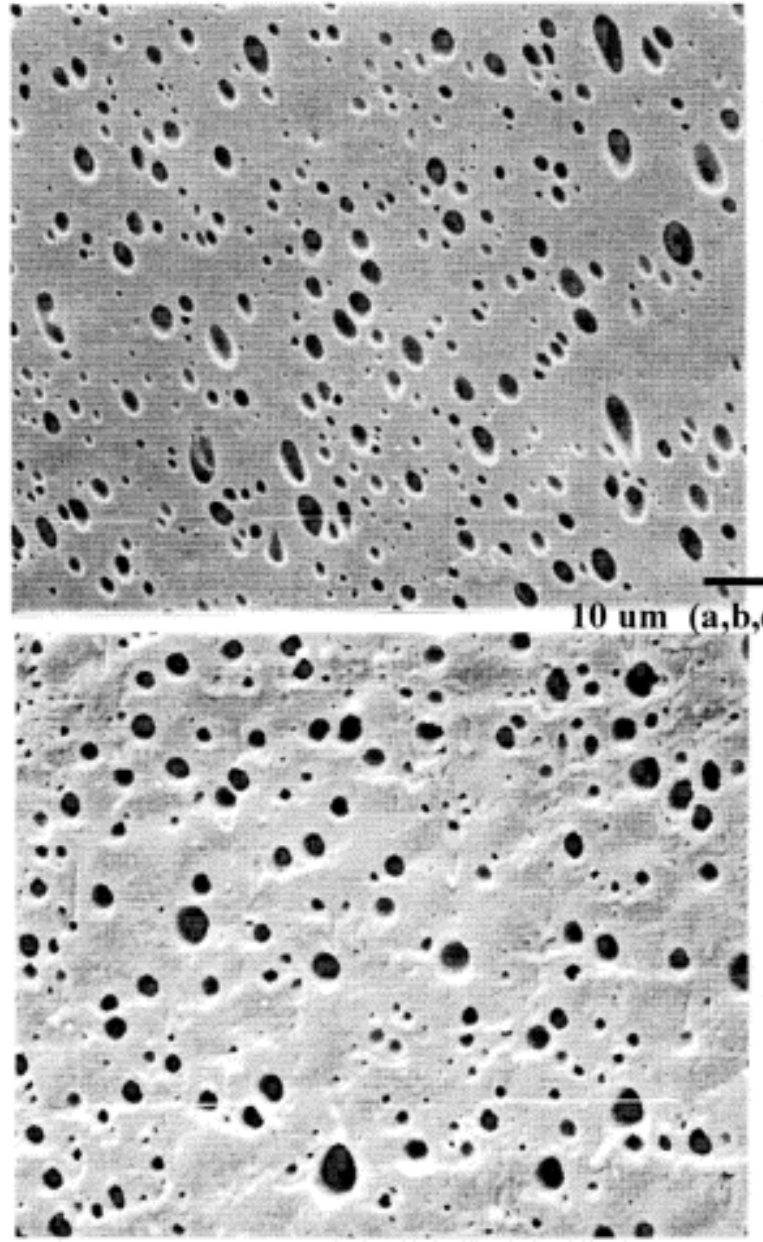

(c) (b)
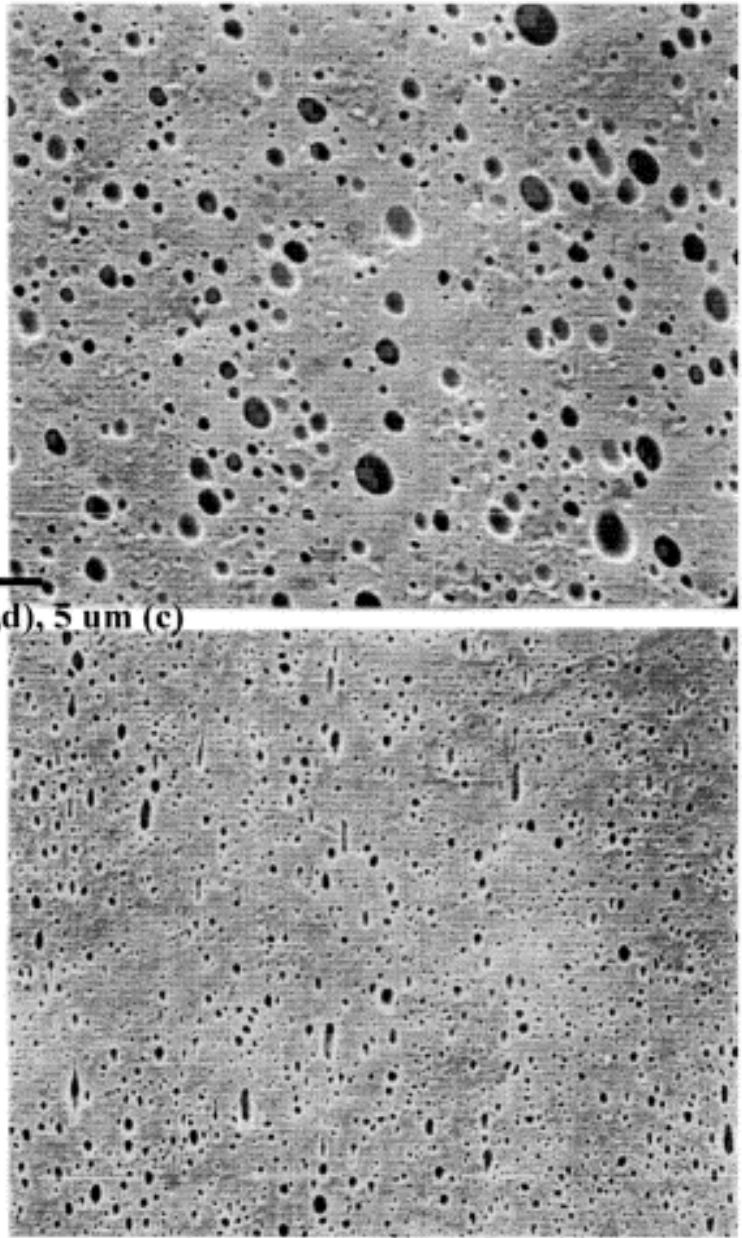

(d)

Fig. 4. SEM of cryo-smoothed and THF etched surfaces of 80LDPE/20PS+(Tr) Triblock copolymer: (a) 1, (b) 2, (c) 5 and (d) $10 \mathrm{wt} \%$.

In all the investigated 80LDPE/20PS blends PS forms the dispersed phase, the computed size of which has been plotted as a function of the added amount of copolymer in Fig. 5. The emulsification curve for the blends added with the tapered copolymer (Tp) clearly shows a plateau in the PS particle size as soon as the copolymer concentration exceeds $2 \mathrm{wt} \%$. When the pure diblock (Pr) is used, this quasi-equilibrium particle size of about $0.4 \mu \mathrm{m}$ is observed only when the copolymer concentration is ca. three times higher. Finally, the PS phase diameter goes on decreasing steadily when as much as $10 \mathrm{wt} \%$ triblock (Tr) is used. So, the tapered diblock copolymer is by far more efficient than the two other block copolymers in stabilizing PS dispersions in LDPE, at least during the melt blending process at $200^{\circ} \mathrm{C}$. Only $2 \mathrm{wt} \%$ tapered diblock allow for a constant average particle diameter of $0.4 \mu \mathrm{m}$ to be reached under the processing conditions of this work, this size being four fold smaller compared to the unmodified blend. When the pure diblock is used, twice that amount is needed to promote the same effect, whereas a four times higher amount of triblock is necessary to reach the same target. 


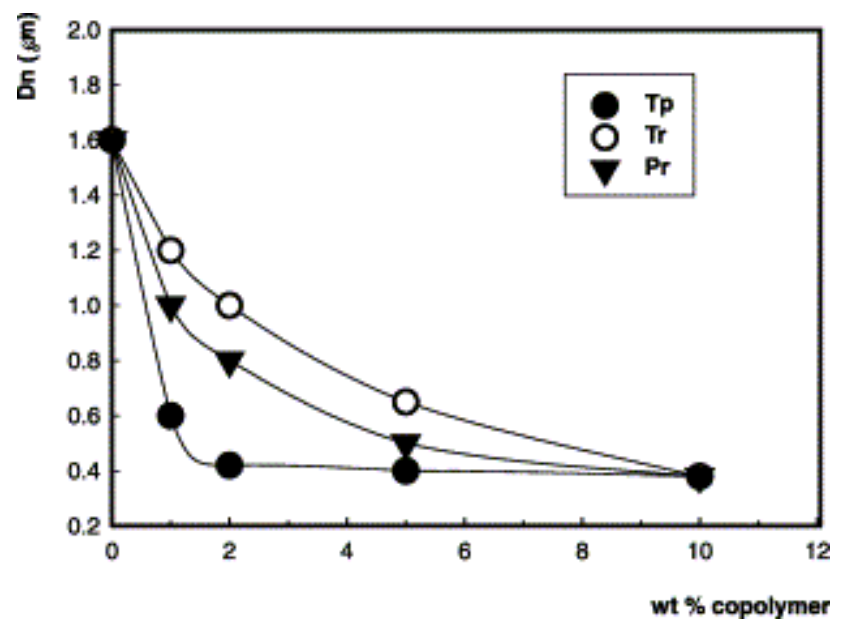

Fig. 5. 80LDPE/20PS: PS particle diameter vs. added amount of copolymer.

It is worth mentioning how sensitive the compatibilization to the nature of the blend components and the molecular characteristics of the selected compatibilizing copolymer. Indeed, no significant differences between a tapered and a pure diblock copolymer was reported for the emulsification of an EPR dispersions in PS matrix [21]. Although the copolymers used are similar to the ones reported herein, a direct comparison may not be justified since the base blends are not similar. Nevertheless, the discrepancies give rise to two interesting fundamental questions: - what is the extent of miscibility between EPR and the hydrogenated polybutadiene block of the copolymer compared to that of LDPE or HDPE as previously reported [21]? Very small differences in miscibility may result in considerable effect on the efficiency of emulsification. In our system, PS constitutes the dispersed phase whereas in the EPR/PS blend system EPR forms the dispersed phase. These differential behavior once more suggest how subtle is the compatibilization of immiscible polymer blends using copolymers of versatile molecular characteristics and architecture.

Based on the present investigation, a HPB-PS diblock copolymer of a tapered structure is probably the most unstable in both homopolymers PS or LDPE. As a result, it efficiently diffuses under shear to the LDPE/PS interface. Whereas, in the case of the triblock copolymer, where the tendency to micellization in LDPE is to be expected, the interfacial activity seems to result from partial location of the copolymer at the interface by shear driven entrapment. When a pure diblock is used, an intermediate effect is observed. Indeed higher amount compared to the tapered was needed for comparable emulsifying activity.

\subsection{Tensile properties}

The ultimate tensile strength $\left.\sigma_{\mathrm{b}}\right)$ and elongation at break $\left(\boldsymbol{t}_{\mathrm{b}}\right)$ of the 80LDPE/20PS blends, unmodified and added with, 2, 5 and $10 \mathrm{wt} \%$ of each type of copolymer, respectively, are reported in Fig. $6 \mathrm{a}$ and $\mathrm{b}$. An ultimate tensile strength of $8.5 \mathrm{MPa}$ and an elongation at break of $30 \%$ are a clear indication of the poor mechanical properties of the unmodified 80LDPE/20PS blend. The addition of as low as $2 \mathrm{wt} \%$ of each of the three block copolymers greatly improves this deleterious behavior. For instance, the tapered diblock copolymer imparts to the blend a two-fold higher ultimate tensile strength, $15 \mathrm{Mpa}$, and an elongation at break which is an order of magnitude higher compared to the neat blend, 330\%. Furthermore, any further increase in the copolymer content no longer changes the ultimate properties in a very significant manner. Fig. $6 \mathrm{a}$ and $\mathrm{b}$ show that the ultimate mechanical properties of the 80LDPE/20PS blend depend on the copolymer content in a way that changes with the 
copolymer structure. That effect of the copolymer architecture on the tensile properties is similar to that observed for the emulsification curve in Fig. 5. When the triblock copolymer is used, the elongation at break exhibits a plateau-like tendency whereas the tensile strength, which is more sensitive to the interfacial adhesion, continues to increase in a quasi-linear manner with the added amount of copolymer. When the pure diblock is used, a change in the curve slope is observed at a concentration of about $5 \mathrm{wt} \%$. This differential behavior is in good agreement with the emulsification curves shown in Fig. 5 where a plateau in PS phase size reduction is observed at a concentration of $2 \mathrm{wt} \%$ for the tapered modified blends, at about $5 \mathrm{wt} \%$ for the pure modified ones and that no visible plateau is observed when the triblock copolymer is used.
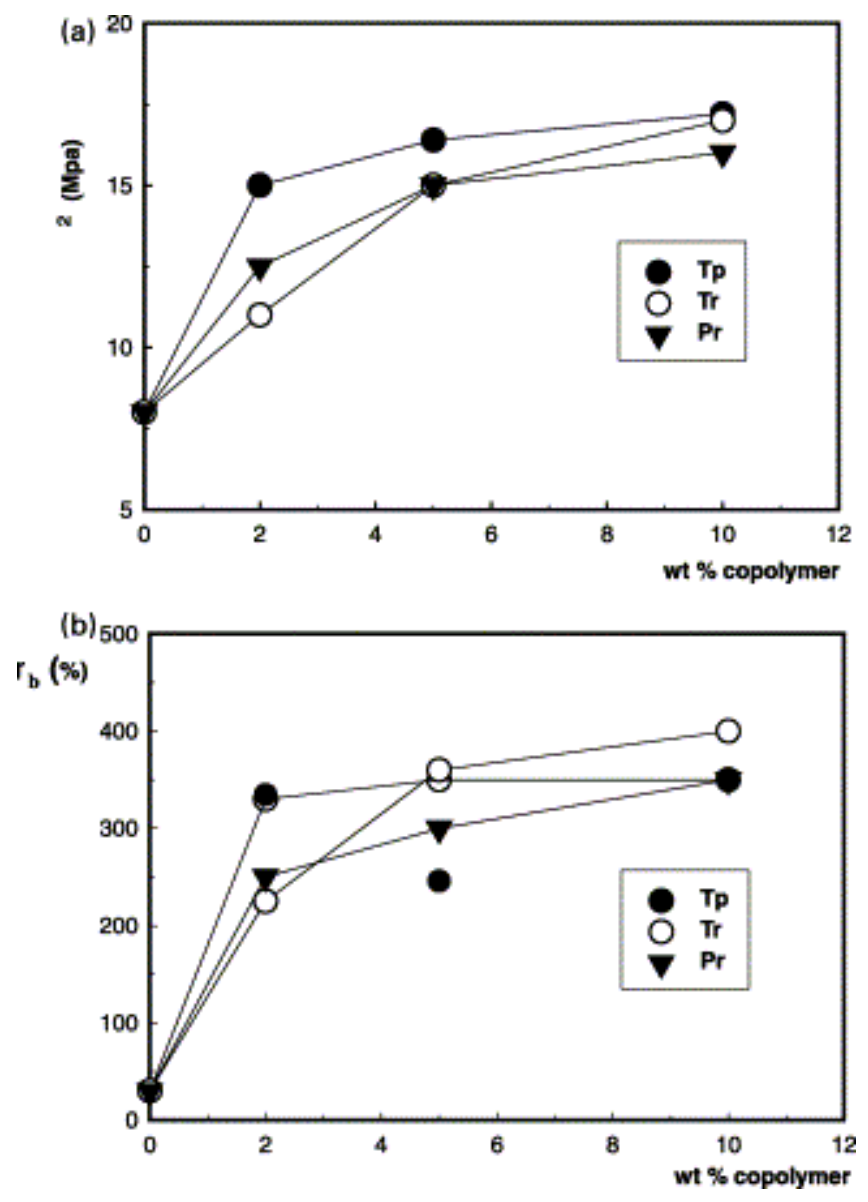

Fig. 6. 80LDPE/20PS: (a) tensile strength and (b) elongation at break vs. added copolymer.

In addition to the ultimate tensile properties discussed above, the shape of the stress-strain curves allows a better insight into the differential behavior in interfacial activity exhibited by the three copolymers under investigation.

The stress-strain curves of the modified blends, shown in Fig. 7, Fig. 8 and Fig. 9, exhibit the same general tendency. However, at a concentration of $2 \mathrm{wt} \%$, the triblock modified blend exhibits an abrupt yielding due to sudden necking observed in the tensile specimen during the deformation process. The yielding observed can be ascribed to a lack of interfacial adhesion imparted by the triblock copolymer to the blend. As shown in the emulsification curve (Fig. 5) it seems that at a concentration of $2 \mathrm{wt} \%$ the triblock copolymer has not efficiently covered the LDPE/PS interface. As a direct consequence of that deficiency, instantaneous and localized stress concentration areas are developed. At higher concentrations, i.e. 5 and $10 \mathrm{wt} \%$ 
no significant differences are observed in the shape and pattern of the stress-strain curves of the three copolymer-modified blends. The yielding exhibited by the triblock modified blends, has clearly disappeared at these concentrations. It has been shown recently that a weak interfacial strength between polyethylene and PS layers resulted when a thin layer of PS- $b$ HPB copolymer, which is not able to saturate the interface, was used. Whereas, when a thicker copolymer layer resulting in interface over-saturation was used, the interfacial strength was considerably increased [22].

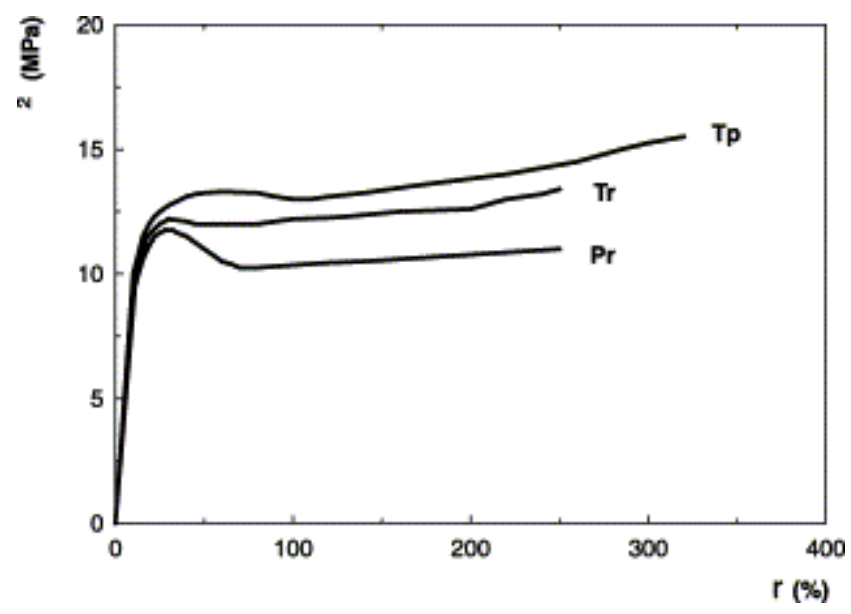

Fig. 7. Stress-strain curve of $80 L D P E / 20 P S+2$ wt $\%$ copolymer.

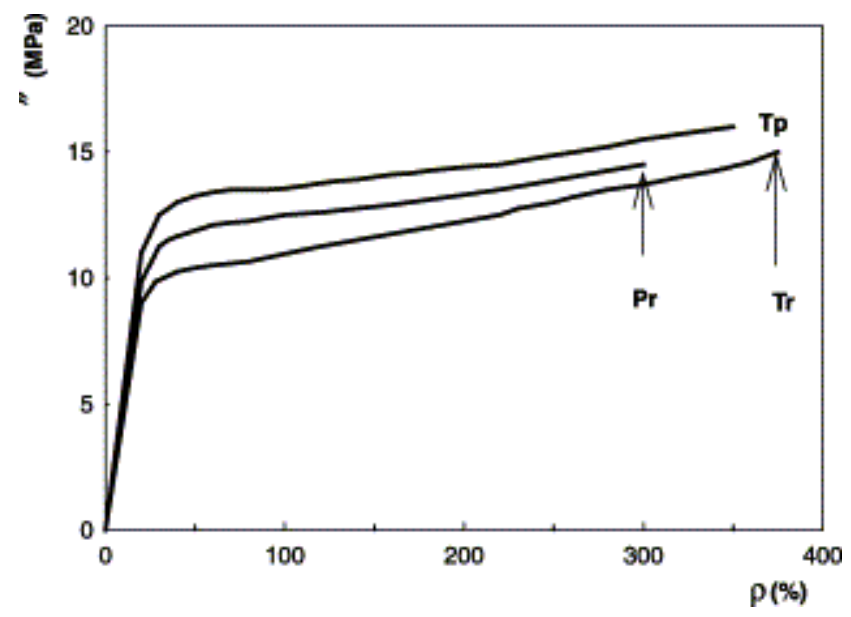

Fig. 8. Stress-strain curve of 80LDPE/20PS +5 wt\% copolymer. 


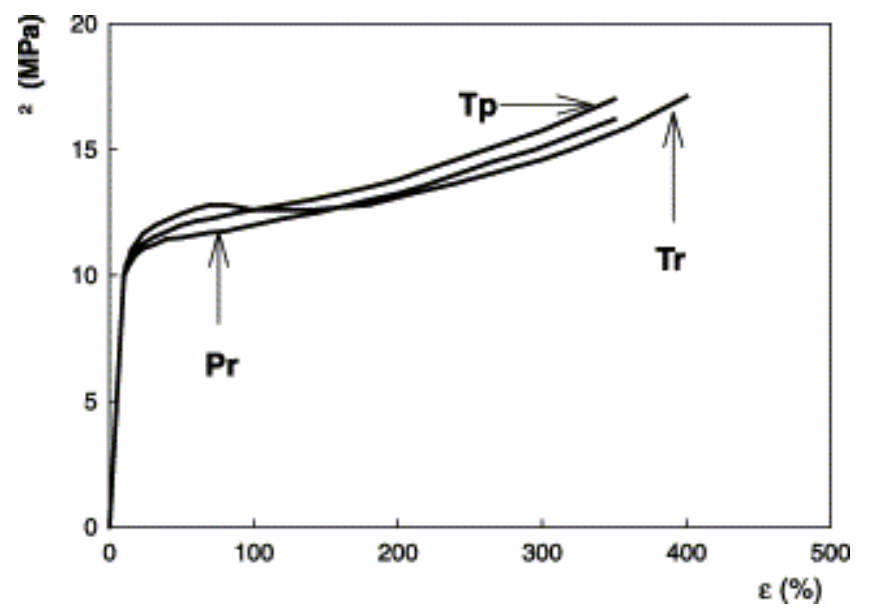

Fig. 9. Stress-strain curve of $80 L D P E / 20 P S+10$ wt $\%$ copolymer.

\subsection{Viscosity behavior}

The interfacial interaction that the copolymers should induce in the blend is expected to also modify its viscous behavior at low frequency. Indeed, the rheological properties such as viscosity and storage modulus at the melt state were previously used to elucidate the interfacial activity of block and graft copolymers in immiscible polymer blends. Under nearly similar experimental conditions, that is, measurement at low frequency in the dynamic mode of test, Brahim et al. [23] showed that an important increase in the low frequency viscosity of 80HDPE/20HIPS was observed when the concentration of either a tapered or a pure HPB- $b$ PS diblock added to these blends was increased. The yield value of the storage modulus was reported to be higher than that of the loss modulus when $5 \mathrm{wt} \%$ of SEB (styrene/ethylene-cobutylene/styrene) triblock copolymer was added to LDPE/PS blends [24].

In Fig. 10 the dynamic viscosity of the blends is plotted as a function of the $\mathrm{wt} \%$ of the added copolymer at a constant frequency of $5 \times 10^{-2} \mathrm{rad} / \mathrm{s}$. This figure is constructed from individual viscosity-frequency plots obtained for each copolymer modified blend.

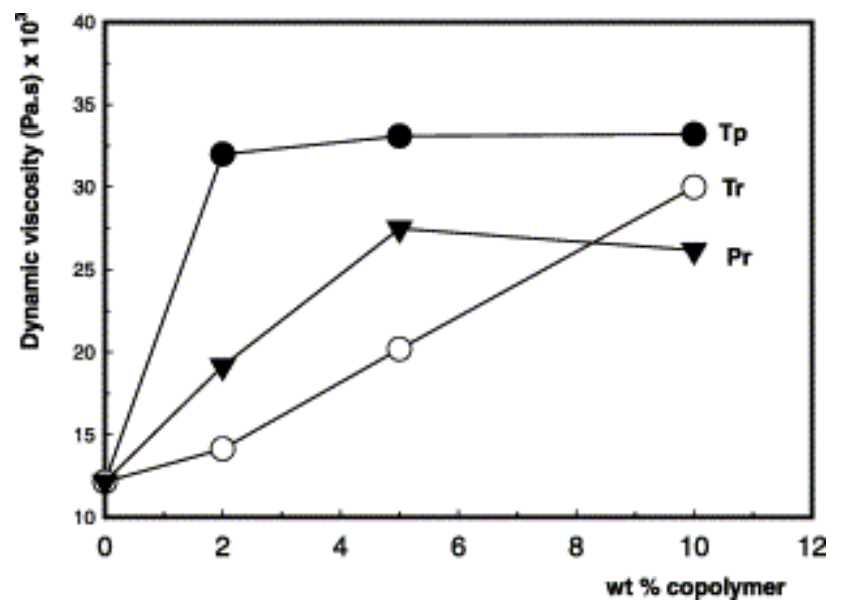

Fig. 10. 80LDPE/20PS: Dynamic viscosity (determined at $5 \times 10^{-2} \mathrm{rad} / \mathrm{s}$ ) vs. \% of added copolymer.

The addition of $2 \mathrm{wt} \% \mathrm{Tp}$ to the blend results in an increase by a factor of 3 of its viscosity which levels off at higher concentration. This is once more an additional indication of the 
efficiency of the tapered copolymer in inducing high interface interaction at a concentration as low as $2 \mathrm{wt} \%$. A continuously increasing viscosity with copolymer concentration is observed for the triblock copolymer. This result is in good agreement with the emulsification curve and the tensile properties described above. The triblock copolymer either has a strong tendency to form its own domain in either of the phases or forms a thicker interphase, which can be considered as a third phase forming a shell around the PS particles. When the pure diblock copolymer is used, a plateau in viscosity is reached at a concentration of about $5 \mathrm{wt} \%$.

The additional information brought by the dynamic viscosity measurements carried out at low frequency evidences that:-the optimum interfacial activity is reached at around $2 \mathrm{wt} \%$ tapered diblock, at about $5 \mathrm{wt} \%$ of the pure diblock copolymer and, no optimum is observed in the case of the triblock copolymer within the investigated range of concentrations.

\subsection{Blends stability versus isothermal annealing}

Tensile properties and phase size measurements were carried out on thermally $\left(180^{\circ} \mathrm{C}\right)$ annealed 80LDPE/20PS blends added with $10 \mathrm{wt} \%$ of the pure diblock, the tapered diblock and the triblock copolymers, respectively.

As shown in Fig. 11a and b, where $20 \mathrm{wt} \%$ PS is dispersed in LDPE matrix, the PS phase exhibits in the absence of interfacial agents about a four-fold size increase when the blend is annealed for $150 \mathrm{~min}$ at $180^{\circ} \mathrm{C}$.

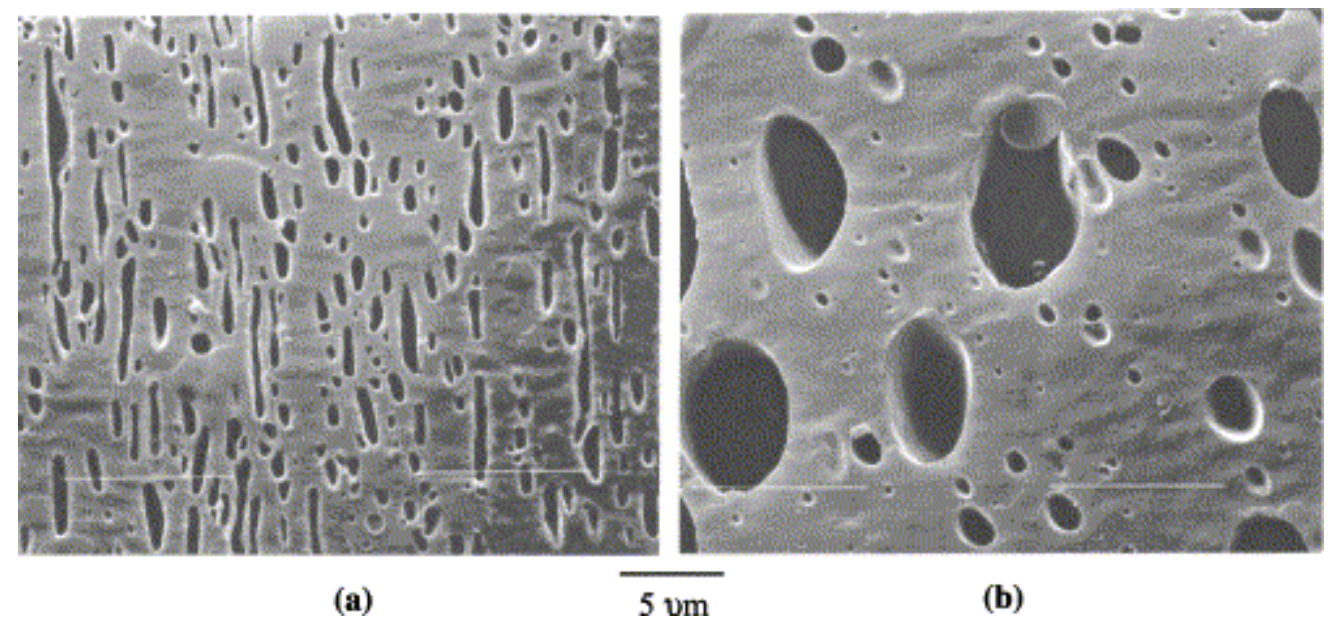

Fig. 11. SEM of cryo-smoothed and THF etched surfaces of 80LDPE/20PS without copolymer: (a) non-annealed (b) annealed (for 150 min at $180^{\circ} \mathrm{C}$ ) samples.

Almost a bimodal distribution of particle size is developed in the annealed blends (Fig. 12a and $b$ ). The bimodal distribution can easily be explained if one considers that both coalescence and rupture occurs competitively. The latter is expected since cylindrical shaped particles having an aspect ratio (length/diameter) higher than 10 are observed in the initial (non-annealed) blend. The addition of a tapered or a pure diblock copolymer to the same blends almost completely suppresses this phase coarsening process. This is confirmed in Fig. 13 and Fig. 14 on SEM micrographs showing the state of dispersion of, respectively, $10 \mathrm{wt} \%$ of the pure diblock and the tapered modified blends, non-annealed and annealed for $150 \mathrm{~min}$ at the same temperature $\left(180^{\circ} \mathrm{C}\right)$. The histograms presented in Fig. 15 and Fig. 16 showing the particle size distribution in these blends reveal no significant broadening. In the case of the 
triblock copolymer added at the same concentration and annealed for the same time and temperature, however, an important PS phase growth (Fig. 17a and b) with a broader particle size distribution (Fig. 18a and b) is observed. The average PS particle size was coarsened by almost a factor of 1.5 , which is really considerable for a $10 \mathrm{wt} \%$ copolymer modified blend.
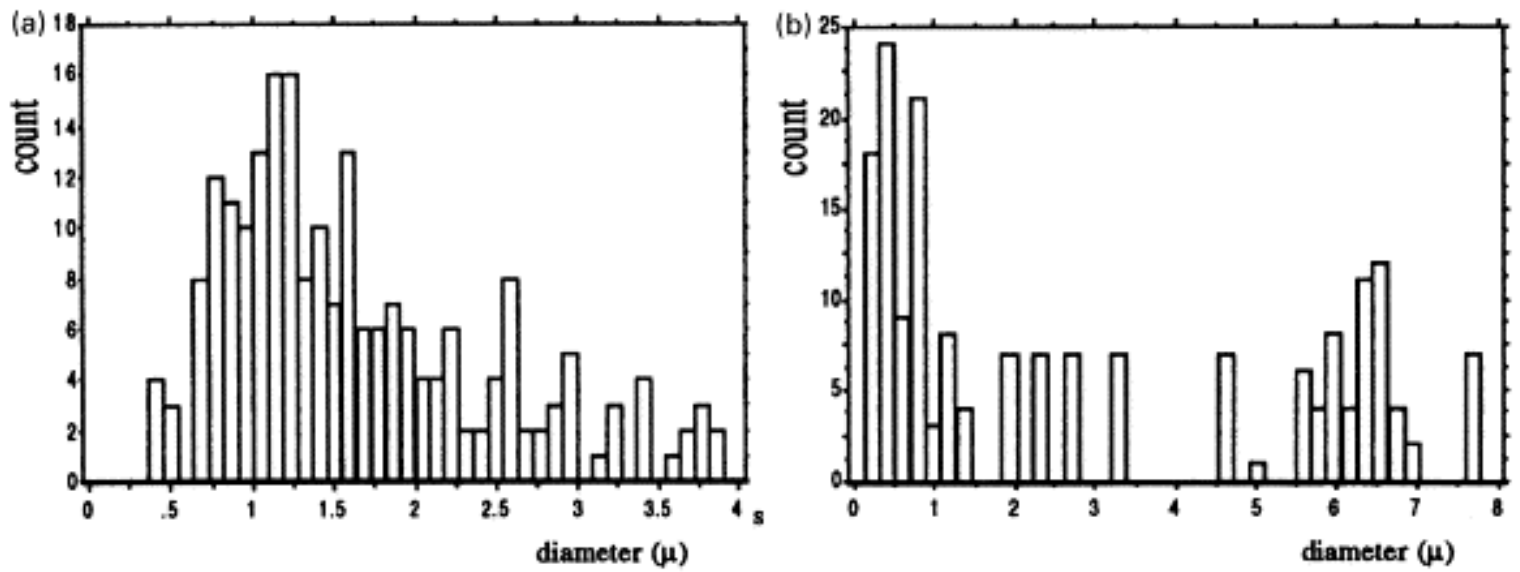

Fig. 12. Particle size distribution: 80LDPE/20PS without copolymer: (a) non-annealed and (b) annealed for $150 \mathrm{~min}$ at $180^{\circ} \mathrm{C}$.

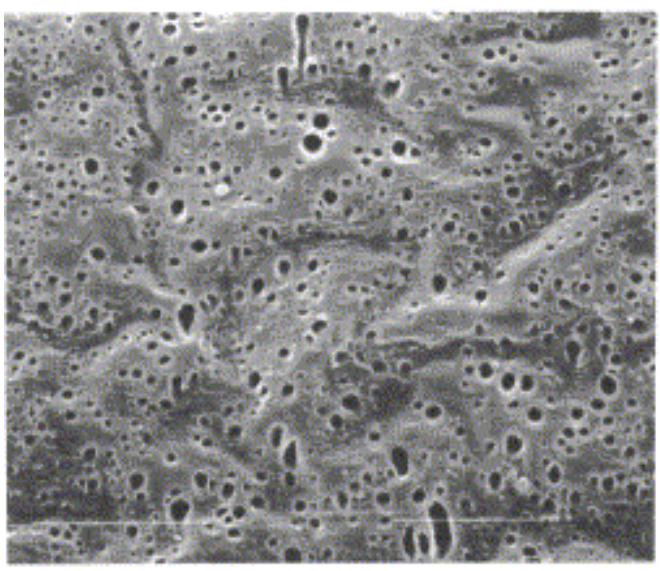

(a)

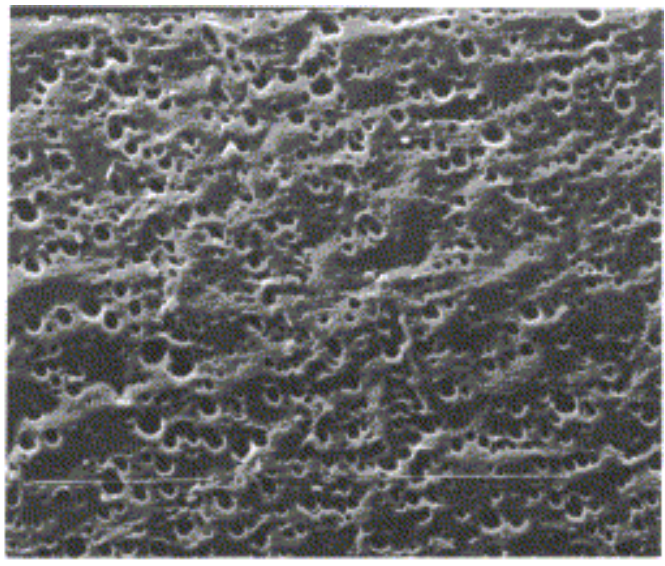

(b)

Fig. 13. SEM of cryo-smoothed and THF etched surfaces of 80LDPE/20PS+10 wt $\%$ tapered diblock (Pr): (a) non-annealed (b) annealed (for $150 \mathrm{~min}$ at $180^{\circ} \mathrm{C}$ ) samples.

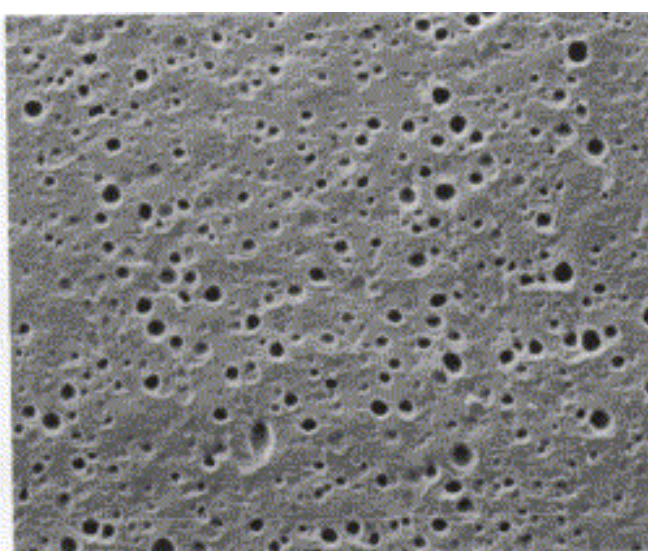

(a)

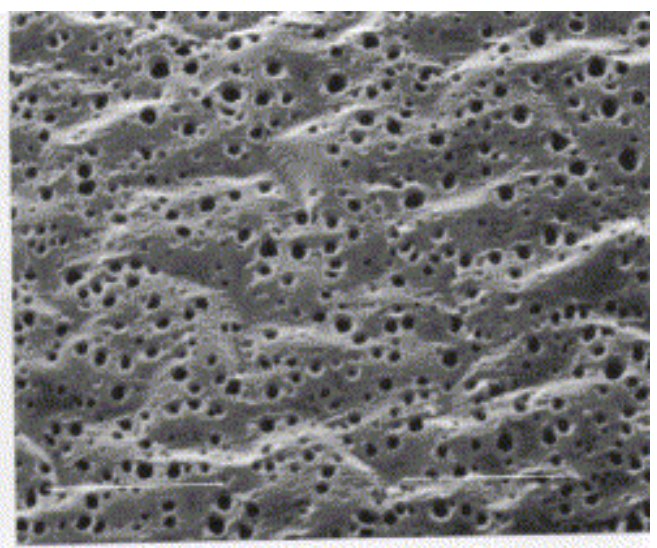

(b) 
Fig. 14. SEM of cryo-smoothed and THF etched surfaces of $80 \mathrm{LDPE} / 20 \mathrm{PS}+10 \mathrm{wt} \%$ (Tp) pure diblock: (a) non-annealed (b) annealed (for $150 \mathrm{~min}$ at $180^{\circ} \mathrm{C}$ ) samples.
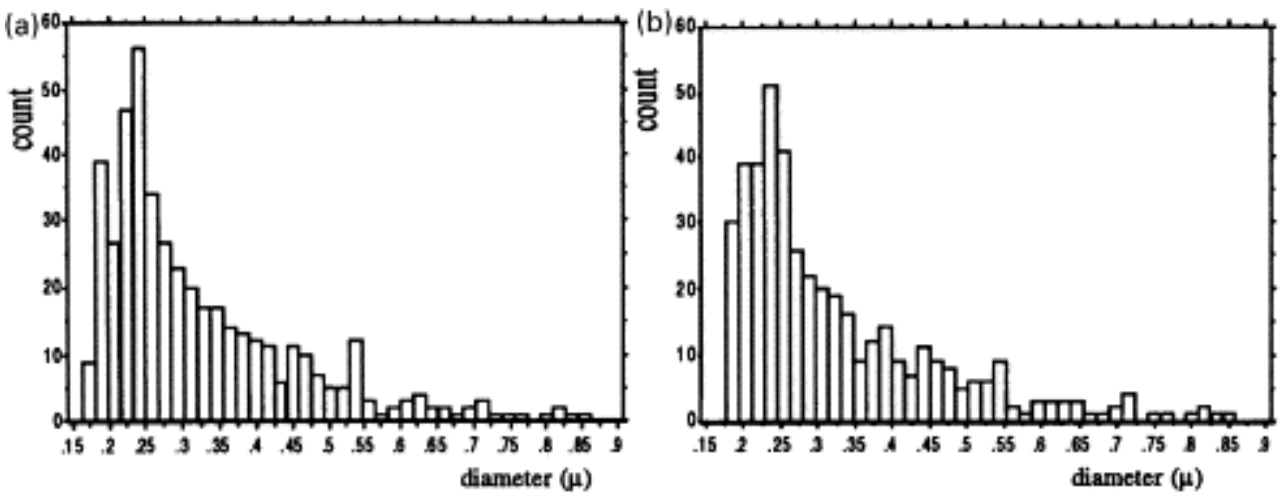

Fig. 15. Particle size distribution: 80LDPE/20PSPS +10 wt\% pure diblock (Pr): (a) nonannealed and (b) annealed for $150 \mathrm{~min}$ at $180^{\circ} \mathrm{C}$.
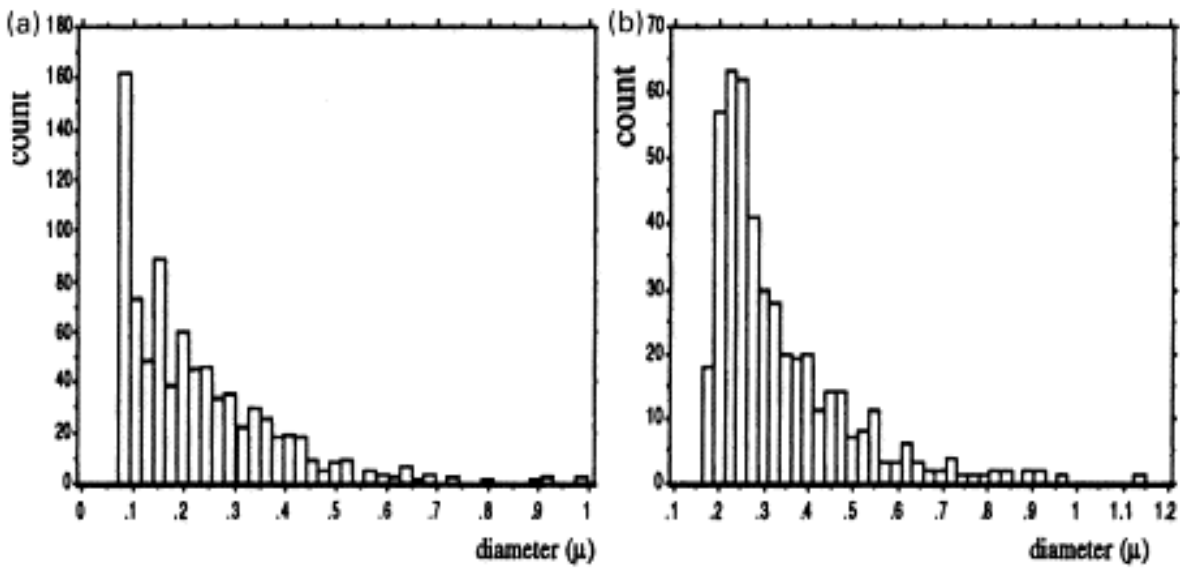

Fig. 16. Particle size distribution: 80LDPE/20PSPS+10 wt\% tapered diblock (Tr): (a) nonannealed and (b) annealed for $150 \mathrm{~min}$ at $180^{\circ} \mathrm{C}$.

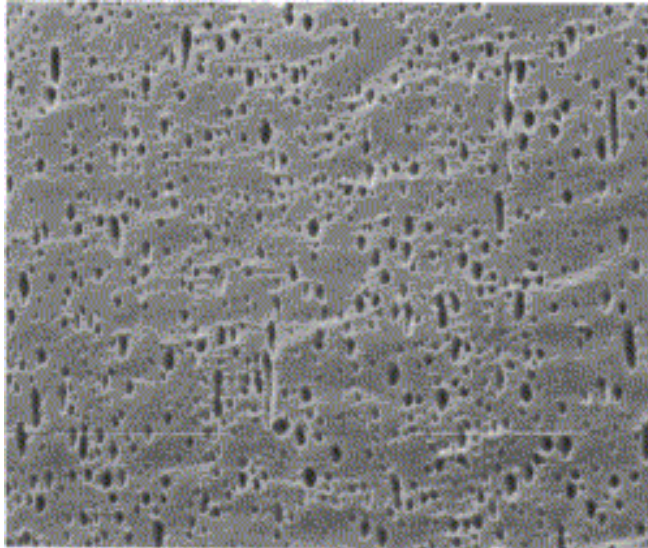

(a)

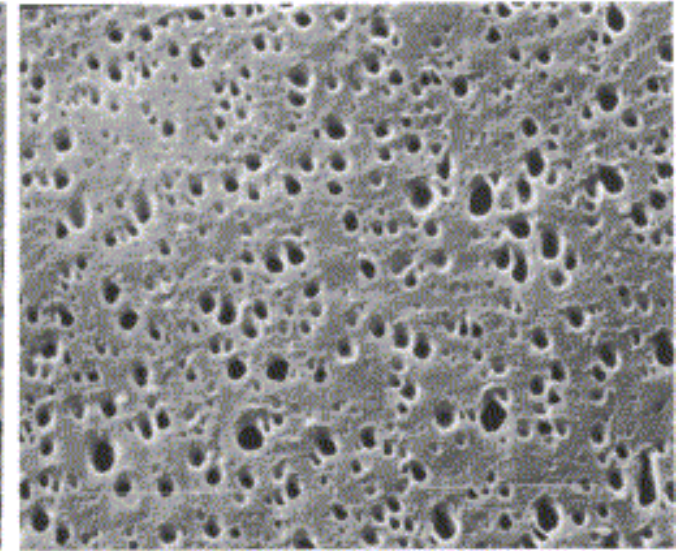

(b)

Fig. 17. SEM of cryo-smoothed and THF etched surfaces of 80LDPE/20PS $10 \mathrm{wt} \%$ (Tr) triblock: (a) non-annealed (b) annealed (for 150 min at $180^{\circ} \mathrm{C}$ ) samples. 

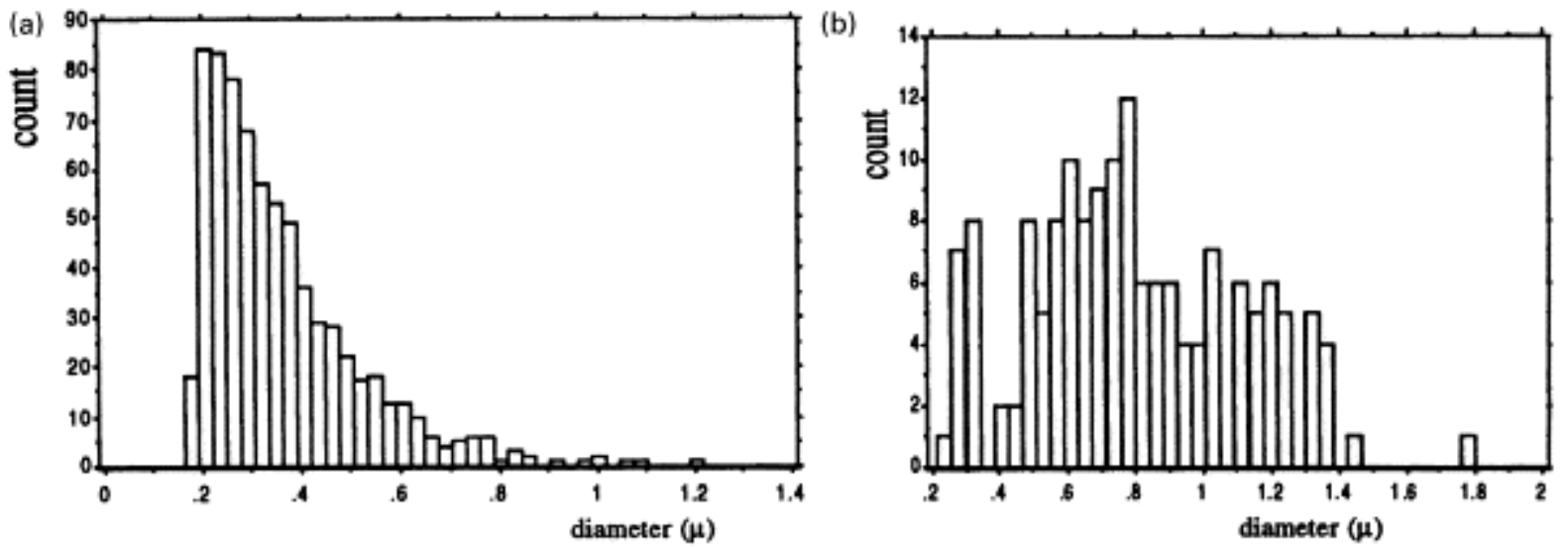

Fig. 18. Particle size distribution: 80LDPE/20PSPS+10 wt\% triblock (Tr): (a) non-annealed and (b) annealed for $150 \mathrm{~min}$ at $180^{\circ} \mathrm{C}$.

From these simple experiments it appears that the pure and the tapered diblock copolymers induce a more stable interfaces in blends of 80LDPE/20PS than does the triblock copolymer.

In Fig. 19a and $\mathrm{b}$ are plotted the tensile strength and elongation at break of the unmodified and copolymer modified blends as a function of the annealing time. The following tendencies are observed: both elongation and tensile strength at break increase upon annealing in the case of the unmodified blend. This behavior was expected since, as shown in Fig. 11a and b the shape of PS particles changed from a spheroid and a cylinder-like geometry to a more or less spherical shape. In this way, stress concentrations are more relaxed. Also, the formation during annealing of smaller, $0.4-0.8 \mu \mathrm{m}$, particles result in an important elongation increase. The development of voids from small particles is a strain consuming process of deformation. 
a)

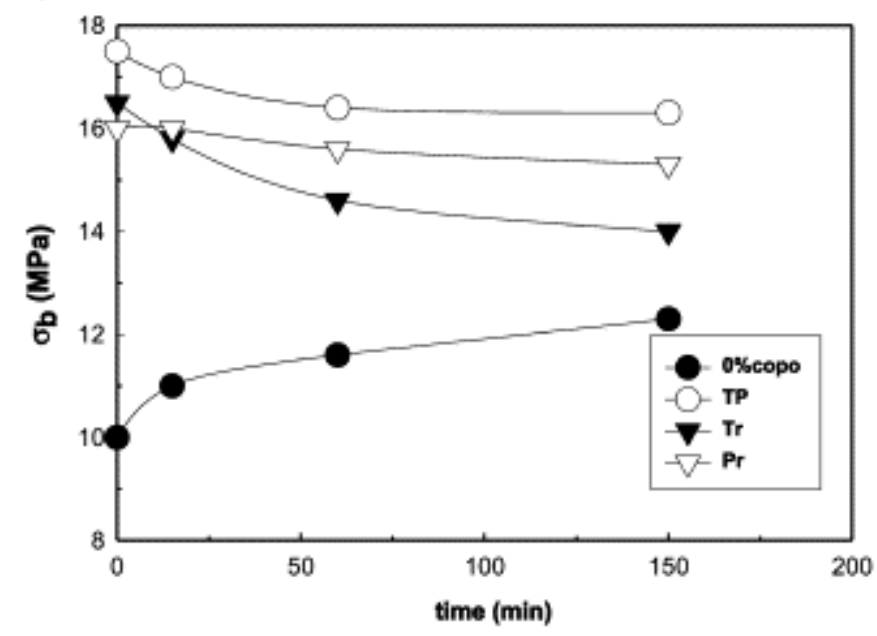

b)

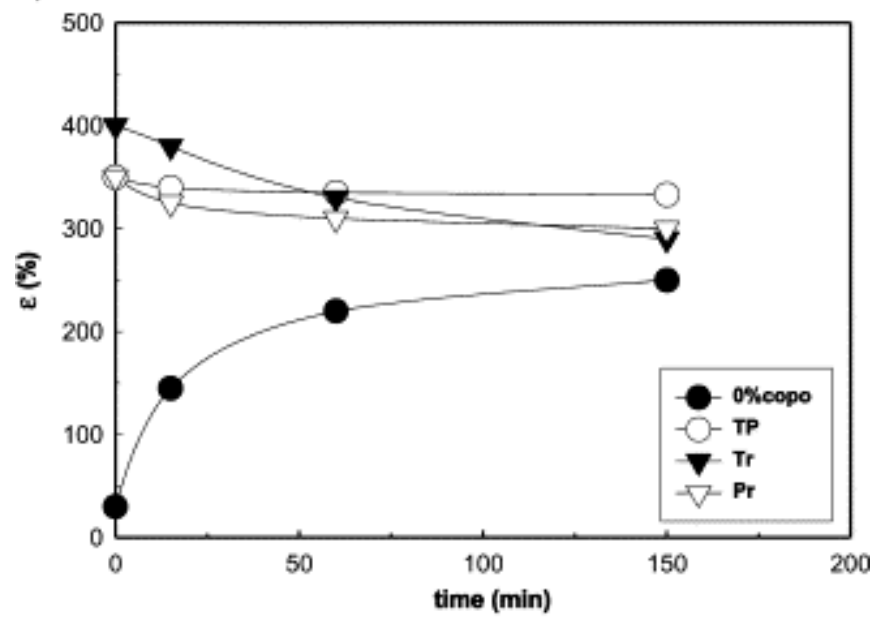

Fig. 19. 80LDPE/20PS +10 wt\% copolymer: (a) Tensile strength at break vs. annealing time, (b) Elongation at break vs. annealing time.

In the case of the pure or the tapered diblock modified blends no significant decrease in either tensile strength or elongation at break is observed, whereas, a considerable deterioration of these properties is observed when the triblock copolymer is used. This is assumed to result from interfacial adhesion weakening, as a consequence of copolymer reorganization in its own phase either at, or after exclusion from the interface. These results constitute additional evidence of the thermally unstable interface induced by the triblock copolymer in LDPE/PS of a PS dispersed phase in LDPE matrix.

\section{Conclusions}

The reported results reveal clearly that a tapered diblock copolymer exhibits an efficient emulsifying activity in 80LDPE/20PS blend where PS forms the discrete dispersed phase in the LDPE matrix. As low as $2 \mathrm{wt} \%$ of the tapered diblock are sufficient to reach a plateau-like property - concentration dependence. About $5 \mathrm{wt} \%$ of the pure diblock were needed to obtain almost the same effect and no visible plateau is observed when a triblock is used. This is assumed to result from a less quantitative, localization of these two copolymers i.e. the pure diblock or the triblock at the LDPE/PS interface. The diblock copolymer most probably 
distribute partly in PS, however, the triblock might micellize in LDPE phase.

\section{References}

[1] Janssen J. PhD Thesis, Eindhoven University of Technology, 1993.

[2] Elemans PHM. PhD Thesis, T.U. Eindhoven, 1989.

[3] Elmendorp JJ. PhD Thesis, T.U. Delft, 1986.

[4] Favis BD, Chalifoux JP. Polym Engng Sci 1987; 27:1591.

[5] Dedecker K, Groeninckx G. Polymer 1998; 39:4993.

[6] Fayt R, Jérôme R, Teyssié Ph. Makromol Chem 1986; 187:837.

[7] Heikens D, Barentsen W. Polymer 1977;18:69.

[8] Willis JM, Favis BD. Polym Engng Sci 1988;28:1416.

[9] Hoen NG. PhD Thesis, Technische Hogeschool Eindhoven, 1977.

[10] Fayt R, Jérôme R, Teyssié Ph. J Polym Sci, Polym Phys Ed 1989; 27:775.

[11] Harrats C, Blacher S, Fayt R, Jérôme R, Teyssié Ph. J Polym Sci, Phys Ed 1995;33:801.

[12] Harrats C, Fayt R, Jérôme R, Teyssié Ph., in press.

[13] Yu W, Zhou C, Inoue T. J Polym Sci, Part B: Polym Phys 2000; 38:2378.

[14] Fortenly I, Kovar. J Polym Compos 1988; 9:119.

[15] Sundararaj U, Macosko CW. Macromolecules 1995; 28:2647.

[16] Jang BZ. Rubber Chem Technol 1984;57:291.

[17] Mirabella FM. J Polym Sci, Part B: Polym Phys 1994; 32:1205.

[18] Pascault JP, Frèrejean V, Taha M. Polym Process Soc (Strasbourg) August, 29 1993:31.

[19] Matos M, Lomellini P, Tremblay A, Lepers J-C, Favis BD. Polym Process Soc

(Strasbourg) August, 29 1993:31.

[20] Wu S. Polymer 1985; 26:1855.

[21] Cigana P, Favis BD, Jérôme R. ACS Prepr 1995; 73:16.

[22] Hermes HE, Bucknall DG, Higgins JS, Scherrenberg RL. Polymer 1998; 39:3099.

[23] Brahim B, Ait-Kadi A, Ajji A, Jérôme R, Fayt R. J Rheol 1991; 35(6):1069.

[24] Utracki L, Sammut P. Ninth Annual NRCC/IMRI Symposium, Poly-blends-88, April 5 and 6, Boucherville, Canada, 1988. 